\title{
Implementation of the Artificial Feeders in Hematophagous Arthropod Research Cooperates to the Vertebrate Animal Use Replacement, Reduction and Refinement (3Rs) Principle
}

\author{
André Luis Costa-da-Silva ${ }^{1,2 *}$, Danilo Oliveira Carvalho ${ }^{1,2}$, Bianca Burini Kojin ${ }^{3}$ and Margareth Lara Capurro ${ }^{1,2 *}$ \\ ${ }^{1}$ Departamento de Parasitologia, Instituto de Ciências Biomédicas, Universidade de São Paulo, São Paulo, SP 05508-000, Brazil \\ ${ }^{2}$ Instituto Nacional de Ciência e Tecnologia em Entomologia Molecular, INCT-EM, Rio de Janeiro, Brazil \\ ${ }^{3}$ Department of Molecular Biology and Biochemistry, 2305 McGaugh Hall, University of California, Irvine, CA 92697-3900, USA
}

\begin{abstract}
Vector-borne diseases are transmitted to humans by hematophagous arthropods and these blood-sucking organisms are target to researches worldwide. The laboratory colonization of these species is an important factor in the development of innovative strategies to control these vectors. However, this maintenance requires blood to make these invertebrates able to complete their life cycle. Although live vertebrate animals are frequently used for this feeding procedure, artificial feeders are available as potential alternatives to replace the use of live animals in some situations, especially in vector colony maintenance. The aim of this commentary is to discuss the use of artificial feeding methods concerning the 3Rs principle application. The scientific community focused on vector-borne diseases studies needs to strongly consider these artificial feeding options as a bioethical alternative to maintain blood-feeding arthropods in laboratory.
\end{abstract}

Keywords: Artificial feeder; Blood-sucking arthropods; Bloodfeeding; Three Rs principle; Use of laboratory animals

\section{Introduction}

Many species of blood-sucking arthropods transmit different human pathogens during the blood-feeding behavior. Consequently, these organisms are targets for different types of basic and applied research worldwide in an attempt by the scientific community to develop innovative strategies for controlling disease transmission by vectors [1]. Studies benefit tremendously when these species can be colonized in laboratory insectary facilities but in this case, to complete the life cycle, these anautogenous organisms necessarily require a blood meal to produce their eggs and small vertebrate laboratory animals like mice, rabbits, chickens and guinea pigs are frequently used as blood suppliers [2].

Obviously, the use of live animals for this purpose is only authorized after bioethical certification by animal care committees under frequently revised protocols. They describe in detail the animal anesthetization or immobilization procedures before the invertebrate feeding process as well as the method for euthanasia when an experiment is completed. It is recommended that protocol evaluations by bioethical committees take into account the $3 \mathrm{Rs}$ principle (replacement, reduction, refinement) related to animal welfare [3,4]. The application of the 3Rs guiding principle strongly contributes to ethical use of animals $[5,6]$, and the invertebrate's engorgement in laboratory conditions involving live animals it is not the only option, given the published literature in this field.

\section{Artificial Feeders}

Based on the pioneering apparatus, a Rutledge feeder [7], many articles have addressed this issue in the previous decades and a large proportion of them developed creative adaptations to promote the construction of different feeders for blood-sucking invertebrate organisms with easily accessible materials [8-20]. Most of these feeders are composed of a heating element (for blood warming) and a feeding part containing a blood reservoir and an artificial membrane surface simulating a vertebrate skin. Although natural membranes can also be applied, there are artificial options to replace the use of animal skin [2]. The large number of different feeders available for mosquito species is notable and the availability of artificial systems for arachnids, phlebotomines and triatomines is also considerable $[8,12,13,19,21]$.

These devices reveal the replacement to the use of live animals is feasible with respect to blood delivery for invertebrate vectors. Much of the published data involving artificial feeders' application is focused on vector in vitro/artificial infection establishment. There is a dependency on the use of artificial infection procedures in the laboratory, to closely mimic the host pathogen relationship, in pursuance of more accurate study vector-borne diseases. In these cases, infected blood is prepared by mixing the pathogenic agent with defibrinated/anti-coagulated blood and the mixture is offered to blood-sucking vectors via artificial feeders.

Nowadays commercial blood from sheep, horse and bovine are good sources for defibrinated blood due to lower cost compared to small vertebrate animals, also larger amounts of blood can be acquired without harming or having to perform euthanasia of donor animals representing a valuable refinement of laboratory animal's usage.

\section{Application in Colony Maintenance}

When the purpose is not to obtain experimental infection but to

*Corresponding author: André Luis da Costa-da-Silva, Departamento de Parasitologia, Instituto de Ciências Biomédicas, Universidade de São Paulo, São Paulo, SP 05508-000, Brazil, Tel: +55-11-30917336; Fax: +55-11-3091-7417; E-mail: alcosta@icb.usp.br

Received October 13, 2013; Accepted December 28, 2013; Published January 02, 2014

Citation: Costa-da-Silva AL, Carvalho DO, Kojin BB, Capurro ML (2014) Implementation of the Artificial Feeders in Hematophagous Arthropod Research Cooperates to the Vertebrate Animal Use Replacement, Reduction and Refinement (3Rs) Principle. J Clin Res Bioeth 5: 167. doi:10.4172/2155-9627.1000167

Copyright: () 2014 Costa-da-Silva AL, et al. This is an open-access article distributed under the terms of the Creative Commons Attribution License, which permits unrestricted use, distribution, and reproduction in any medium, provided the original author and source are credited. 
Citation: Costa-da-Silva AL, Carvalho DO, Kojin BB, Capurro ML (2014) Implementation of the Artificial Feeders in Hematophagous Arthropod Research Cooperates to the Vertebrate Animal Use Replacement, Reduction and Refinement (3Rs) Principle. J Clin Res Bioeth 5: 167. doi:10.4172/2155-9627.1000167

Page 2 of 3

maintain colonies in laboratory facilities, the use of the artificial feeders is not prioritized as can be observed in the methods section of a large number of published articles. This led us to ask an important question: how viable these apparatuses can be in relation to maintenance of species' life cycles in the laboratory? It is a crucial point to be addressed since the argument here is to promote an ethical conscience based on 3Rs principle to increase the artificial feeder application in substitution for live animal use to blood-feed invertebrate vectors. In fact, although some articles reported negative effects on fecundity caused by artificial blood-feeding for Rhodnius prolixus and Simulium damnosum [22,23], there are many works showing positive examples in which colonies maintained by artificial feeders are comparable to live animal-fed counterparts for different species $[9,11,16,18,21,24-26]$.

In addition to laboratory studies, mass rearing facilities for vector control programs through population suppression, such as SIT (Sterile Insect Technique) or RIDL (Release of Insects containing a Dominant Lethal) programs $[27,28]$ are under development. To achieve a mass production of insects, a great amount of blood is periodically necessary to maintain egg production without compromising production or releases. A realistic estimative can be performed as an example: a single insect can ingest $3.5 \mu \mathrm{L}$ of blood, considering the mean of a mouse blood volume is $1.5 \mathrm{~mL}, 560$ mice would be necessary per week to supply a mass production of 240,000 mosquito females. For those large facilities artificial blood systems are welcome and recommended [29]. Liters of blood can be easily obtained daily from abattoirs or bought from other suppliers.

These results argue favorably for the replacement of live animal use by artificial feeders, generating a lower demand of small vertebrate animals, nonetheless it is important to highlight that a comparative evaluation in relation to colony fitness consequences is necessary in each specific case. In the same way, variation in the reproductive fitness of a colony maintained by an artificial feeding process can also be attributed to the blood source as examples have demonstrated for some mosquito species [30-32]. Since defibrinated blood originating from different vertebrate species is commercially available, multiple sources can be tested in order to achieve the best artificial feeding performance. Moreover, one recent article demonstrated that outof-date human blood from blood banks can be used [25] as a viable alternative to artificially feed two mosquito species, although the age of out-of-date blood ( 5 to 25 days post-expiration date) shows a negative effect on mosquito fecundity. The authors suggested that out-of-date human blood can be used for this purpose since expired blood bags are discarded as biological waste. Obviously, bioethical concerns, local/ institutional ethics committee's evaluation, certifications and blood bank authorization need to be obtained before this blood source can be applied as a laboratory option to artificially feed colonized vectors, and appropriate blood tests need to be adopted to prevent accidental infections.

\section{Conclusion}

In summary, the relevant aspects of artificial feeders usage described here strongly support the reduction, replacement and refinement of live animals for maintenance and experimentation of blood-sucking insects' colonies. Those aspects are fully supported by scientific research in this field.

This positioning has the intention to bring awareness for the feasibility of artificial feeders utilization in entomology laboratories and finally the research community could start to change the way they perform their experiments over time. Although this is the purpose of the current commentary, artificial feeders are not only suggested as laboratory alternatives to hematophagous arthropods. A recent article proposed the use of these devices as agents for controlling mosquitoborne diseases by satiating mosquitoes with food from the artificial feeders therefore reducing the number of human mosquito meals [33]. The proposal in the present work is much less ambitious and innovative but is totally founded in considerations of animal welfare and application of the 3 Rs principle.

\section{References}

1. Javed S, Khan F, Ramirez-Fort M, Tyring SK (2013) Bites and mites: prevention and protection of vector-borne disease. Curr Opin Pediatr 25: 488-491.

2. Benedict MQ (2009) Bloodfeeding: Membrane Apparatuses and Animals Methods in Anopheles Research. MR4.

3. 3. Russel WMS, Burch RL (1959) The Principles of Humane Experimental Technique. Methuen and Co. Ltd, London, UK.

4. National Research Council (US) Committee for the Update of the Guide for the Care and Use of Laboratory Animals (2011) Guide for the Care and Use of Laboratory Animals. (8thedn), National Academies Press, Washington (DC), USA.

5. Ferdowsian HR, Beck N (2011) Ethical and scientific considerations regarding animal testing and research. PLoS One 6: e24059.

6. Liebsch M, Grune B, Seiler A, Butzke D, Oelgeschläger 170 M, et al. (2011) Alternatives to animal testing: current status and future perspectives. Arch Toxicol 85: 841-858.

7. Rutledge LC, Ward RA, Gould DJ (1964) Studies on the feeding response of mosquitoes to nutritive solutions in a new membrane feeder. Mosq News 24 407-419.

8. Abel I, Corrêa FN, Castro AA, Cunha NC, Madureira RC, et al. (2008) Artificial feeding of Amblyomma cajennense (Acari: Ixodidae) fasting females through capillary tube technique. Rev Bras Parasitol Vet 17: 128-132.

9. Benzon GL, Apperson CS (1987) An electrically heated membrane blood feeding device for mosquito colony maintenance. J Am Mosq Control Assoc 3: $322-324$.

10. Cosgrove JB, Wood RJ, Petrić D, Evans DT, Abbott RH (1994) A convenient mosquito membrane feeding system. J Am Mosq Control Assoc 10: 434-436.

11. Deng L, Koou SY, Png AB, Ng LC, Lam-Phua SG (2012) A novel mosquito feeding system for routine blood-feeding of Aedes aegypti and Aedes albopictus. Trop Biomed 29: 169-174.

12. Harington JS (1960) A Simple Apparatus for the Artificial Feeding of Rhodnius prolixus (Hemiptera, Reduviidae). Parasitolagy 50: 273-277.

13. Huebner E, Harrison R, Yeow K (1994) A new feeding technique for experimental and routine culturing of the insect Rhodnius prolixus. Can J Zool 72: $2244-2247$

14. Kasap H, Alptekin D, Kasap M, Güzel Al, Lüleyap U (2003) Artificial bloodfeeding of Anopheles sacharovi on a membrane apparatus. J Am Mosq Control Assoc 19: $367-370$

15. Mitsui Y, Miura M (2010) Development of a simple and convenient feeding device to infect Aedes aegypti mosquitoes with Brugia pahangi microfilariae derived from the peritoneal cavity of Mongolian jirds. Trop Med Health 38: 97101.

16. Nasirian H, Ladonni $\mathrm{H}$ (2006) Artificial bloodfeeding of Anopheles stephens on a membrane apparatus with human whole blood. J Am Mosq Control Assoc 22: $54-56$

17. Rampersad J, Ammons D (2007) Versatile blood bags for laboratory feeding of mosquitoes. J Am Mosq Control Assoc 23: 149-152.

18. Tseng M (2003) A simple parafilm M-based method for blood-feeding Aedes aegypti and Aedes albopictus (Diptera: Culicidae). J Med Entomol 40: 588-589.

19. Waladde SM, Young AS, Morzaria SP (1996) Artificial feeding of ixodid ticks. Parasitol Today 12: 272-278.

20. Costa-da-Silva AL, Navarrete FR, Salvador FS, Karina-Costa M, loshino RS, et al. (2013) Glytube: A Conical Tube and Parafilm M-Based Method as a Simplified Device to Artificially Blood-Feed the Dengue Vector Mosquito, Aedes aegypti. PLoS One 8: e53816. 
Citation: Costa-da-Silva AL, Carvalho DO, Kojin BB, Capurro ML (2014) Implementation of the Artificial Feeders in Hematophagous Arthropod Research Cooperates to the Vertebrate Animal Use Replacement, Reduction and Refinement (3Rs) Principle. J Clin Res Bioeth 5: 167. doi:10.4172/2155-9627.1000167

21. Harre JG, Dorsey KM, Armstrong KL (2001) Comparative fecundity and survival rates of Phlebotomus papatasi sandflies membrane fed on blood from eight mammal species. Med Vet Entomol 15: 189-196.

22. Wirtz HP, Raybould JN (1986) Artificial feeding of West African Simulium damnosum Theobald s.I. (Diptera: Simuliidae) through membranes and their subsequent fecundity. Trop Med Parasitol 37: 143-148.

23. Chiang RG, Chiang JA (2010) Feeding through artificial membranes reduces fecundity for females of the blood-feeding insect, Rhodnius prolixus. Arch Insect Biochem Physiol 74: 103-113.

24. Mann RS, Kaufman PE (2010) Colonization of Lutzomyia shannoni (Diptera: Psychodidae) Utilizing an Artificial Blood Feeding Technique Colonization of Lutzomyia shannoni (Diptera: Psychodidae) utilizing an artificial blood feeding technique. 35: 286-294.

25. Pothikasikorn J, Boonplueang $R$, Suebsaeng C, Khaengraeng $R$, Chareonviriyaphap T (2010) Feeding response of Aedes aegypti and Anopheles dirus (Diptera: Culicidae) using out-of-date human blood in a membrane feeding apparatus. J Vector Ecol 35: 149-155.

26. Rowton ED, Dorsey KM, Armstrong KL (2008) Comparison of in vitro (chickenskin membrane) versus in vivo (live hamster) blood-feeding methods for maintenance of colonized Phlebotomus papatasi (Diptera: Psychodidae). J Med Entomol 45: 9-13.
27. Dyck V, Hendrichs J, Robinson AS, Klassen W, Curtis C (2005) History of the Sterile Insect Technique. Sterile Insect Technique. Springer, The Netherlands, 3-36.

28. Alphey L (2002) Re-engineering the sterile insect technique. Insect Biochem Mol Biol 32: 1243-1247.

29. Benedict MQ, Knols BGJ, Bossin HC, Howell PI, Mialhe E, et al. (2009) Colonisation and mass rearing: learning from others. Malar J 8: S4.

30. Bennett GF (1970) The influence of the blood meal type on 244 the fecundity of Aedes ( Stegomyia ) aegypti L. (Diptera: Culicidae). Can J Zool 48: 539-543.

31. Richards SL, Anderson SL, Yost SA (2012) Effects of blood meal source on the reproduction of Culex pipiens quinquefasciatus (Diptera: Culicidae). J Vector Ecol 37: 1-7.

32. Lyimo IN, Keegan SP, Ranford-Cartwright LC, Ferguson HM (2012) The impact of uniform and mixed species blood meals on the fitness of the mosquito vector Anopheles gambiae s.s: does a specialist pay for diversifying its host species diet? J Evol Biol 25: 452-460.

33. Egeth M, Kurzban R (2012) Artificial natural selection: can supplemental feeding domesticate mosquitoes and control mosquito-borne diseases? Evol Psychol 10: 602-610. 